\title{
IJIREEICE
}

\section{Current Transformer Adequacy}

\author{
Aalakh Devari ${ }^{1}$, Devendra Sutar ${ }^{2}$, Pritam Thomke ${ }^{3}$ \\ Electronics and Telecommunication Dept., Goa College of Engineering, Farmagudi, Ponda Goa, India ${ }^{1,2}$ \\ Research \& Development Dept., Siemens Ltd., Verna Industrial Estate, Verna, Goa, India ${ }^{3}$
}

\begin{abstract}
Current Transformer is mainly used to convert high primary current in the power system to the level which can be handled by electromechanical or microprocessor based Relays and metering devices. The current transformer should be chosen correctly for a particular application considering the burden connected to the secondary, primary fault current and X/R ratio of the system. Over dimensioned or under dimensioned CT can cause mal-operation of relays. In this study, we have developed a windows application to check whether CT selected for particular application having certain burden is adequate or not. If in case the selected CT is not adequate then the application will suggest new CT design to avoid saturation. Proper Selection of CT is required for good protection scheme requirement.
\end{abstract}

Keywords: Current Transformer saturation, X/R ratio, Burden, AC and DC saturation.

\section{INTRODUCTION}

Current Transformer is basic part of protective system as it provide proportional safe amount of current to protection and measurement devices. The main purpose of Current transformer is to convert high primary fault current to small secondary current which is acceptable to devices connected to the secondary side of current transformer. The conversion of primary current to secondary current is governed by the turn's ratio neglecting the errors as shown in the formula below

$$
\mathbf{I}_{\mathrm{S}}=\mathbf{I}_{\mathbf{P}} / \mathbf{N} \quad-1
$$

Where $I_{p}$ - primary current,

$I_{s}$ - secondary current

$\mathrm{n}$ - Turns ratio

The secondary current of CT is either $1 \mathrm{~A}$ or $5 \mathrm{~A}$ as per standards. Conventional CTs are iron-cored and hence suffers from the problem of core saturation. [1]The CT saturation occurs when the magnetic flux in the core exceeds the linear region on the magnetizing characteristics.

\section{CURRENT TRANSFORMER SATURATION}

The saturation of core mainly depends on the fault current, primary $\mathrm{X} / \mathrm{R}$ ratio, burden connected to the secondary of current transformer and cross-sectional area and magnetic path length of core.

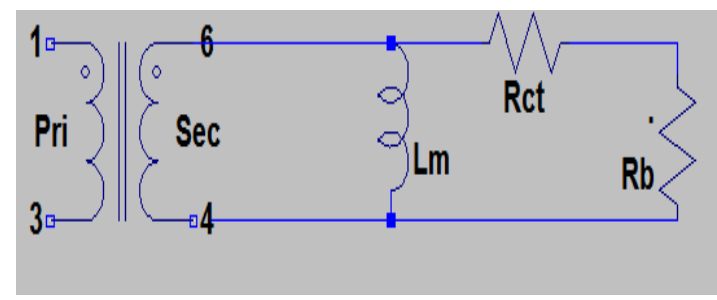

Fig.1. Equivalent circuit of Current Transformer
The error of current transformer is dependent on whether the core is saturated or not. Once core saturates, the ratio and phase error of Current transformer is high. When the core saturates, the magnetizing current is high compared to current flowing through burden.

The saturated and unsaturated waveform of secondary current is shown in figure below.

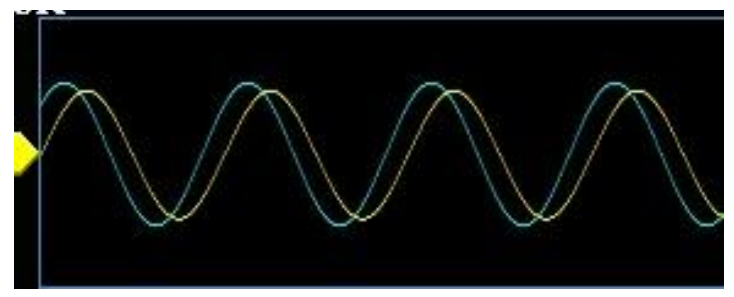

Fig. 2 CT unsaturated waveform

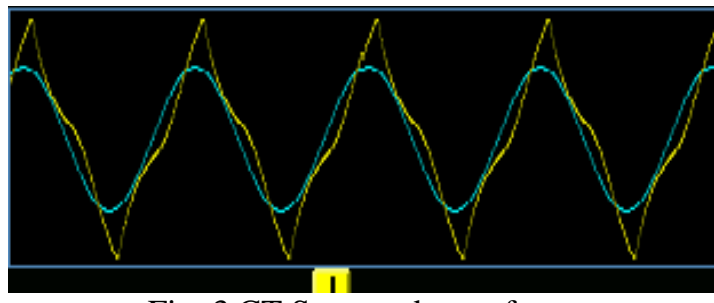

Fig. 3 CT Saturated waveform

Blue wave is primary current and Yellow waveform is secondary current. As shown in fig.1, after saturation the secondary CT current is distorted. These results are obtained practically from CT under test.

When iron core saturates, the inductance Lm becomes low and the total primary current is used to excite the core and the secondary output current is distorted. This condition will persist until the primary current has reduced to the 
value corresponding to the saturation point. From this point onwards, the core comes out of saturation and core flux decays in a transient manner.

Core material (Permeability), cross section area of core and amount of flux required to satisfy the burden requirement of $\mathrm{CT}$ determines the amount of exciting current.

\section{SATURATION DUE TO AC COMPONENT}

AC saturation is caused by high symmetrical current with no dc component. High magnitude of AC current cause large amount flux to be generated which exceeds core capacity to carry flux and hence output current of Current Transformer is distorted

[2]In order to avoid AC saturation condition, the core should be chosen such that the Secondary Saturation voltage, $\mathrm{Vx}$, must satisfy the following equation

$$
\mathbf{V x}>\mathbf{I} \text { * } \mathbf{Z}_{\mathbf{b}}
$$

Where $\mathrm{V}_{\mathrm{x}}-\mathrm{CT}$ saturation voltage

$\mathrm{I}_{\mathrm{s}}$ - CT secondary Current

$\mathrm{Z}_{\mathrm{b}}$ - CT burden

From equation 2, we can observe that saturation of current transformer with no DC offset can be due to high primary current, low Turns ratio or high secondary burden.

\section{SATURATION DUE TO DC COMPONENT}

DC component in primary current can lead faster saturation of current transformer. It is also called as transient saturation. But DC saturation last only till the transients decay enough or vanish to bring current transformer out of saturation region. DC components depends on the primary $\mathrm{X} / \mathrm{R}$ ratio

[2]To avoid DC Saturation, following equation should be satisfied

$$
\mathrm{Vx}>\mathrm{Is} * \mathrm{Z}_{\mathrm{b}} *(1+\mathrm{X} / \mathrm{R}) \quad-3
$$

Where $\mathrm{X} / \mathrm{R}$ - primary system time constant

\section{FACTORS THAT AFFECT SATURATON OF CT}

Saturation of current transformer is one cause of CT errors hence current transformer must be designed or chosen such that Saturation is avoided

Following factors affect saturation of CT

1) Fault Current offset: The primary time constant i.e. $\mathrm{X} / \mathrm{R}$ ratio and the angle at which fault occurs determine fault current offset. Greater the offset, faster the CT saturates
2) Magnitude of fault current: With higher fault current with same degree of DC offset, rate of increase of flux is higher thus causing faster saturation of Current Transformer.

3) Remanent flux: Once CT is saturated, there always remains some amount of flux in the core even if the primary supply is turned off. This remanent flux either adds to or subtracts from, to flux produced by supply. If remanent flux is high then it may cause core saturation instantly.

4) Secondary burden: Higher the secondary burden, more amount of flux is required to meet the burden requirements for the same primary current and hence core saturates faster.

5) Core dimensions: More the cross-section area of the core, more the flux it can carry and avoid core saturation. Therefore keeping all other factor constant, more cross-section area causes saturation point to be higher.

6) Turns ratio: Increasing the number of turns decreases the flux and hence time-to-saturate increases.

\section{CURRENT TRANSFORMER ADEQUACY APPLICATION}

In this application, the selected current transformer will be theoretically analysed whether it will saturate for the given primary current and secondary burden.

If $\mathrm{CT}$ is found to be saturated then user will be notified that the selected Current transformer is not adequate and new Current Transformer design will be suggested.

As shown in figure 4, the user is expected to enter core details and system details.

In System details, the frequency is in Hz. The primary current is the maximum nominal primary current to be measured. Core material is to be chosen from the drop box in the application.

Once all the parameters are correctly entered, user has to press check button to check whether the selected burden is adequate or not

If the selected CT is not adequate for the entered primary current, secondary burden, X/R ratio and No. of turns then CT status will red and new CT design will be suggested as shown in figure 5 .

If the Selected CT is adequate then application will show CT status in greenas shown in figure 6. 
International Journal of Innovative Research in Electrical, Electronics, Instrumentation and Control Engineering

NCAEE 2017

National Conference on Advances in Electrical Engineering

NMAM Institute of Technology, Nitte

Vol. 5, Special Issue 2, April 2017
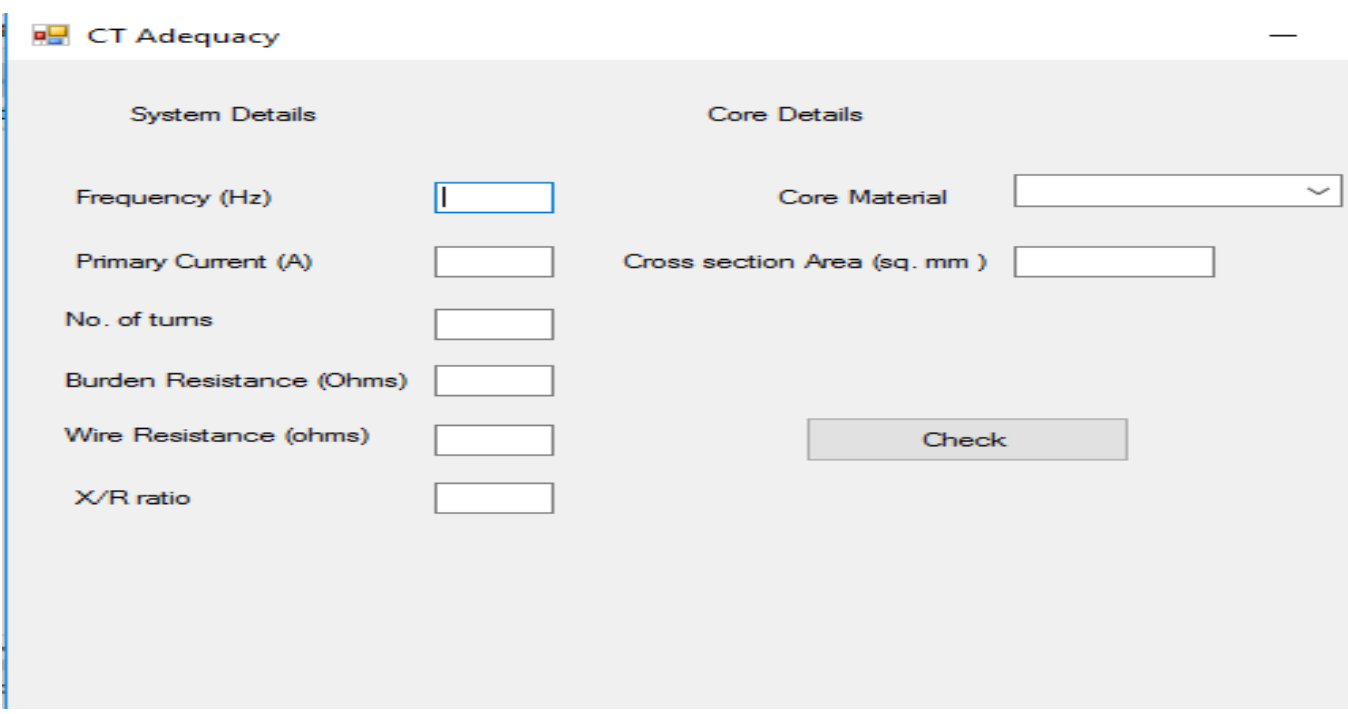

Fig 4: Application Interface

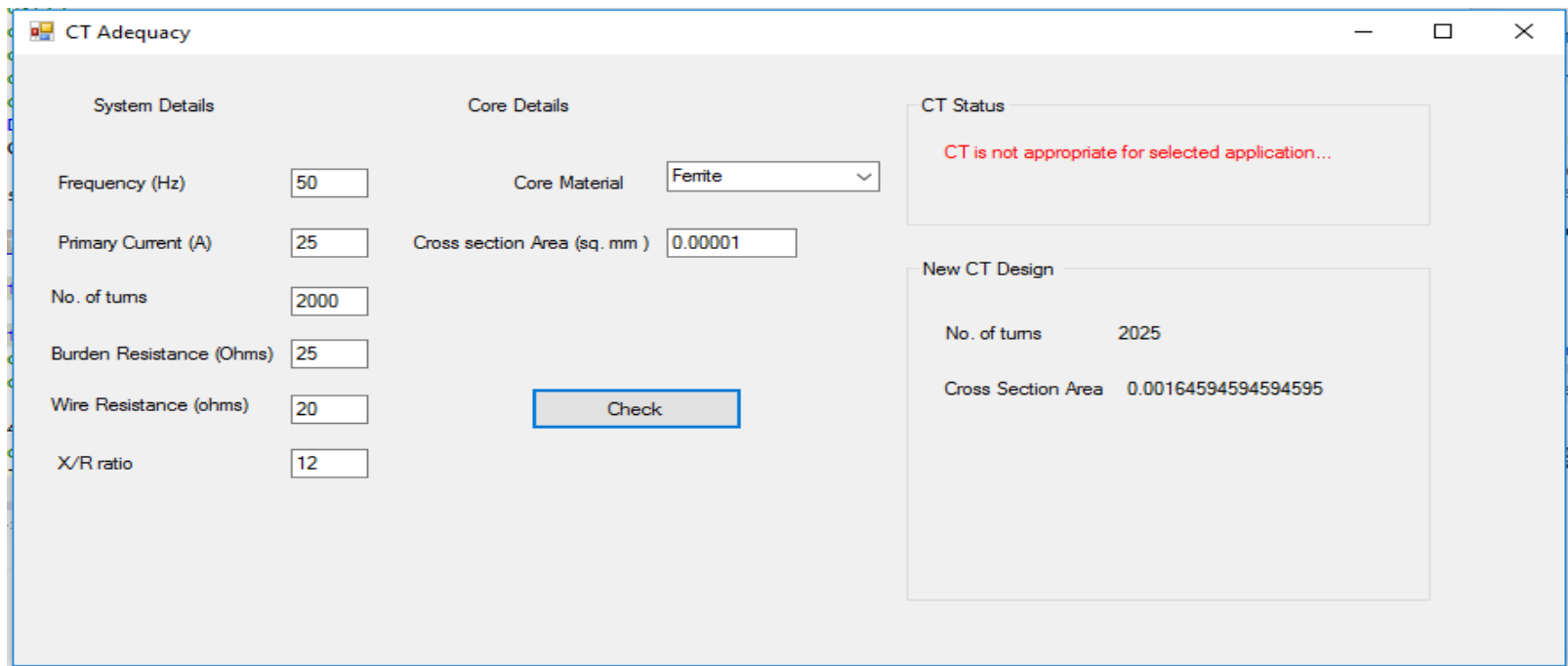

Fig 5: CT design is not adequate

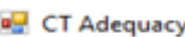

System Details

Frequency $(\mathrm{Hz})$

Primary Current (A)

No. of tums

Burden Resistance (Ohms)

Wre Resistance (ohms)

$X / R$ ratio

$\square \times$

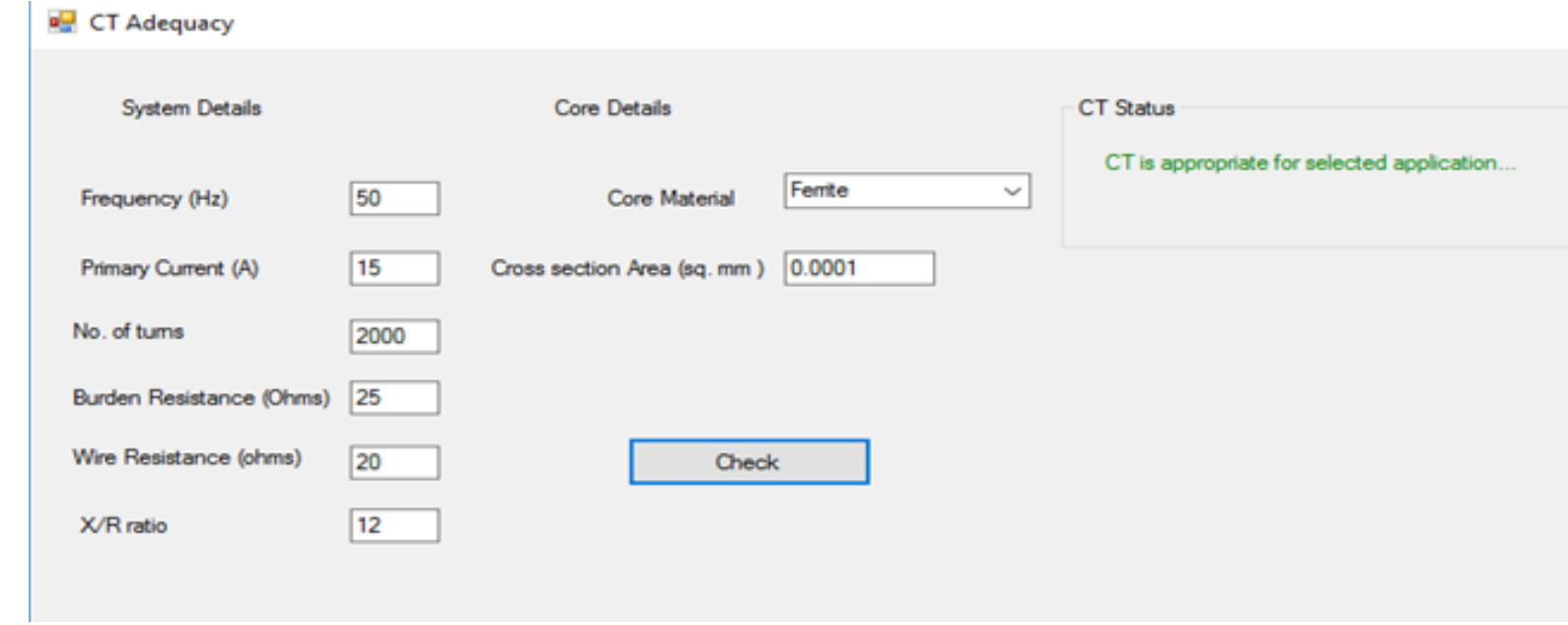

Fig 5: CT design is adequate 


\section{CONCLUSION}

It is important to select appropriate current transformer for relay to operate successfully in case of fault current. For CT to be selected correctly, the core material, number of turns and cross-sectional area should be determined correctly.

In fact, number of turns and cross-section area should determined such that it avoid core to saturate and make current transformer work in linear region where accuracy is high and error are very less.

Using this application, one can check the suitability of the selected current transformer

\section{ACKNOWLEDGMENT}

I am deeply indebted to my guide, Prof. Devendra Sutar, Professor, Department of Electronics and Telecommunication Engineering, and Mr. Pritam Thomke, Hardware Developer, Siemens Ltd., Goa for allowing me to carry out this project under her supervision. He has given me confidence to take up this project and guided me to at times of difficulty.

I thank my teachers, who have taught enthusiastically at the Goa College of Engineering. I also thank Dr. Hassanali Virani, (Head of the Department), Department of Electronics and Telecommunication Engineering and Dr. Vinayak N. Shet(Principal) Goa College of Engineering for allowing me to do this project and providing the necessary infrastructure.

I thank my parents, family members and well wishers, without whom this project would not have taken shape.

\section{REFERENCES}

[1] The CT Behavior and its compatibility with relay protection, Ionuţ Ciprian, U.P.B. Sci. Bull., Series C, Vol. 76, Issue. 3, 2014.

[2] Saturation of Current Transformers and its Impact on Digital Over current Relays Ibrahim. M. El-Amin, Senior Member, IEEE, and Nabil. H. Al-Abbas, Member, IEEE.

[2] A. P. Sachin Tiwari, "Current Transformer Sizing \& Saturation Calculation with Transient Performance Analysis of CT Using ATP Software," International Journal of Advanced Research in Electrical,Electronics and Instrumentation Engineering, Vol. 4, Issue 5, May 2015

[3] M. N. a. G. W. SWIFT, "Dynamic Analysis of a Current Transformer During Faults," Electric Power Systems Research, 1986.

[4] "Guide for the Application of Current Transformers Used for Protective Relaying Purposes," IEEE Standard C37.110-2007, April 2008

[5] A. S. Michał Kaczmarek, "Equivalent circuit parameters of the current transformer with toroidal core in conditions of distorted signals," IEEE, 2010. 